\title{
The Role of Quantitative Electroencephalogram in the Diagnosis and Subgrouping of Attention-Deficit/Hyperactivity Disorder
}

\author{
Su Hyun Bong and Jun Won Kim \\ Department of Psychiatry, Catholic University of Daegu School of Medicine, Daegu, Korea
}

\begin{abstract}
Attention-deficit/hyperactivity disorder (ADHD) leads to functional decline in academic performance, interpersonal relationships, and development in school-aged children. Early diagnosis and appropriate intervention can significantly reduce the functional decline caused by ADHD. Currently, there is no established biological marker for ADHD. Some studies have suggested that various indicators from the quantitative electroencephalogram (QEEG) may be useful biological markers for the diagnosis of ADHD. Until the 2010s, theta/beta ratio (TBR) was a biomarker candidate for ADHD that consistently showed high diagnostic value. However, limitations of TBR have recently been reported. Studies have demonstrated that phase-amplitude coupling, especially theta phase-gamma amplitude coupling, are related to cognitive dysfunction and may assist in the diagnosis of ADHD. As yet, the underlying mechanism is not clearly established, and the clinical efficacy of these biomarkers needs to be proven through well-controlled studies. Based on the heterogeneous characteristics of ADHD, subgrouping through QEEG plays a key role in diagnosis and treatment planning. Sophisticated, welldesigned studies and meta-analyses are necessary to confirm these findings.
\end{abstract}

Key Words: Attention-deficit/hyperactivity disorder; Electrophysiology; Child psychiatry; Theta/beta ratio; Theta phase-gamma amplitude coupling; Subgroup.

Received: April 16, 2021 / Revision: May 3, 2021 / Accepted: May 7, 2021

Address for correspondence: Jun Won Kim, Department of Psychiatry, Catholic University of Daegu School of Medicine, 33 Duryugongwon-ro 17-gil, Nam-gu, Daegu 42472, Korea

Tel: +82-53-650-4786, Fax: +82-53-623-1694, E-mail: f_affection@naver.com

\section{INTRODUCTION}

According to the Diagnostic and Statistical Manual of Mental Disorders, 5th edition (DSM-5), attention-deficit/hyperactivity disorder (ADHD) is characterized by a persistent lack of attention, hyperactivity, and impulsiveness, causing dysfunction in terms of poor academic performance, interpersonal relationships, and development [1]. In most cultures, the prevalence of ADHD is approximately 5\% among children [2]. Among children diagnosed with ADHD, more than 60-85\% satisfy the diagnostic criteria of ADHD until adolescence [3,4], and approximately $40-60 \%$ of children show symptoms of ADHD even after they become adults $[5,6]$. However, ADHDrelated functional impairment can be significantly reduced by early diagnosis and treatment [7].

$\mathrm{ADHD}$ is thought to be caused by defective brain function. However, the pathophysiology of ADHD is currently unclear. ADHD was first defined as a disease in the early 1960s, ADHD

This is an Open Access article distributed under the terms of the Creative Commons Attribution Non-Commercial License (https://creativecommons.org/licenses/by-nc/4.0) which permits unrestricted non-commercial use, distribution, and reproduction in any medium, provided the original work is properly cited. was first defined as 'minimal brain damage (MBD)' [8]. MBD was based on the hypothesis that congenital problems in children's brains would lead to symptoms of decreased attention, hyperactivity, and impulsion. Since then, the biological causes of $\mathrm{ADHD}$ in children have been actively investigated. The main findings suggest that psychostimulants used to treat ADHD. Psychostimulants, such as methylphenidate and amphetamine, play a role in regulating neurochemicals, such as dopamine and norepinephrine. Researchers are also actively conducting studies to identify the aetiologic or diagnostic markers, including mutation of the dopamine transporter 1 gene (DAT1) or dopamine D4 receptor gene (DRD4) [9], and are investigating decreased activities of the prefrontal cortex via functional magnetic resonance imaging (fMRI) [10]. However, there is currently no established diagnostic biomarker for ADHD. In general, ADHD is diagnosed using DSM-5, and standardized psychological tests, including self-reported scales, intelligence tests, and continuous performance tests [11]. Current methods for the diagnosis of ADHD are criticized for potential overdiagnosis. Additionally, the diagnostic accuracy of ADHD is controversial in patients with comorbidities. Consequently, 
recent efforts have been made to study various imaging and neurophysiological tests that can be used to diagnose ADHD with increased accuracy.

Electroencephalogram (EEG) is a non-invasive and safe method that does not expose patients to radiation. It is also relatively cheap and has a high temporal resolution. Therefore, it is used in children and adolescents for both clinical and research purposes. In particular, quantitative EEG (QEEG) provides quantitative measures of brain activity through Fourier transformation, unlike other clinical EEGs used for the diagnosis of epilepsy, monitoring of consciousness during anesthesia, and polysomnography. QEEG is actively utilized for the diagnosis, evaluation, and treatment of various mental disorders, such as depression [12], anxiety disorder [13], schizophrenia [14], substance addiction [15], obsessive-compulsive disorder [16], and ADHD [17]. This review describes the theta/beta ratio (TBR), which is the most studied diagnostic marker of QEEG in children and adolescents with ADHD. TBR and theta phase-gamma amplitude coupling (TGC) are both promising biomarkers. Furthermore, the latest knowledge on subgroup classification using QEEG in children with ADHD has also been addressed.

\section{DIAGNOSIS}

\section{Theta/beta ratio: supporting group}

Patients with ADHD tend to show hypoarousal in their brain function and prominent cortical slowing. These features are indicated by increased slow waves and decreased fast waves in the QEEG [18,19]. Lubar [20] suggested that the TBR is a diagnostic marker that can help diagnose ADHD in children. In QEEG, the brain waves are largely divided into four groups after Fourier transformation according to frequency: delta (1-3 $\mathrm{Hz})$, theta (4-8 Hz), alpha (9-12 Hz), and beta (13-25 Hz). In turn, these are used to measure power.

TBR is the ratio of the theta wave to the beta wave. TBR has been suggested as a method for assessing brain function decline with increased sensitivity compared to evaluating the independent increase and decrease in theta and beta waves, respectively. TBR has mostly been assessed in the vertex, the $\mathrm{Cz}$ electrode, in the resting state. In a large-scale study of $482 \mathrm{pa}-$ tients, Monastra et al. [17] reported $86 \%$ sensitivity and $98 \%$ specificity for the diagnosis of ADHD using TBR in the vertex. Snyder and Hall [21] conducted a meta-analysis of studies on TBR and reported that TBR had a high effect size (approximately 3.08 for the diagnosis of ADHD). Additionally, TBR showed $87 \%$ sensitivity and $94 \%$ specificity for the diagnosis of ADHD in children and adolescents, suggesting that it is more useful than the self-reported scale [22]. In 2013, the Food and Drug Administration (FDA) of the U.S. authorized the Neuropsychiatric Electroencephalograph-Based ADHD
Assessment Aid (NEBA) system to assist in the diagnosis of ADHD. The NEBA system was approved for the diagnosis of ADHD in children and adolescents between the ages of 6 and 17 years. The NEBA system measures TBR. However, the FDA states that ADHD cannot be diagnosed using only the NEBA system and recommends the use of the NEBA system to assist in clinical assessment and diagnosis [23,24].

\section{Theta/beta ratio: opposition group}

Recent literature has reported negativity against the hypoarousal theory as the cause of ADHD. Some studies have also opposed the idea of using increased TBR to assist in the diagnosis of ADHD. The group suggesting the diagnostic value of TBR has argued that an increase in TBR indicates a hypoarousal condition with reduced brain function and that psychostimulants, such as methylphenidate, are effective in treating $\mathrm{ADHD}$, as the patients are in a hypoarousal condition. In contrast, those opposing the diagnostic value of TBR have suggested that TBR has no significant association with skin conductance levels (SCLs) that reflect the arousal of the brain. They argued that a decrease in alpha power is correlated with an increase in SCLs [25,26]. In a study that compared SCLs in ADHD patients with hypoarousal (high TBR) and hyperarousal (high beta) groups, TBR and beta power were not associated with arousal [27]. Based on these findings, the opposing group stated that TBR is associated with cognitive processing capacity rather than hypoarousal. In a follow-up study, TBR was not significantly correlated with the P300 amplitude, which is closely related to the arousal mechanism. Instead, it was correlated with P300 latency, which is closely related to cognitive processing capacity [28]. Moreover, many studies have shown that TBR does not show any statistical significance and has a low accuracy in distinguishing ADHD from healthy controls [2932]. Among these studies, the largest study compared 562 patients with ADHD and 309 healthy controls. In this study, $\mathrm{Cz}$ TBR was not significantly different in ADHD patients versus healthy controls [32]. Based on these findings, a meta-analysis by Arns et al. [33] showed that TBR did not have high reliability regarding ADHD diagnosis, and this was caused by the increase in TBR in the control group due to a decreased sleep time and use of electronic devices.

\section{Theta/beta ratio: the debate}

In 2015, Snyder, the vice president of the NBA Health Company, who worked in the Research \& Development Department, published a large-scale, prospective, triple-blinded, multi-center study, which played a crucial role in TBR being approved by the FDA [34]. In this study, TBR was not used as a simple method to diagnose and distinguish ADHD, but as part of an integrated method that reflected the results of EEG at the dis- 
cretion of the clinician. TBR was not statistically significant in the diagnosis of ADHD. However, it was highly effective (Cohen's d, 1.53) in identifying 'Criterion E', which referred to the differential diagnosis of 'other disorders and conditions' in the DSM-IV-TR-diagnostic criteria. TBR increased the overall accuracy of the diagnosis from $61 \%$ to $88 \%$. Snyder reported that the rapid increase in the prevalence of ADHD over time was clearly correlated with a decreased effect size according to the TBR $\left(\mathrm{R}^{2}=0.89\right)$. This suggests that ADHD has been over-diagnosed in recent years and that ADHD patients with low TBR were being misdiagnosed. Therefore, in patients with other physical or mental disorders that can be mistaken for ADHD, the NEBA system can help in the diagnosis of ADHD at the discretion of the clinician.

The above study was greatly criticized. Loo and Arns [35] pointed out five methodological errors in this study. First, clinicians were instructed to assess ADHD patients as "ADHD-positive" if the primary diagnosis showed clear indications of ADHD. In other cases, the clinicians were instructed to assess as "ADHD-negative." However, "ADHD negative" included secondary and non-ADHD, which led to errors in the interpretation of the results. Second, "DSM criterion E certainty" is a concept that is not related to the presence or absence of ADHD. The NEBA system had no additional clinical value if not needed to diagnose and distinguish ADHD. Third, discrepancies between the clinicians and the multidisciplinary team were interpreted as ADHD overdiagnosis. However, the two groups did not share the same diagnostic. Such errors were not considered. Fourth, patients who responded well to ADHD medications without side effects were considered to have ADHD. However, this is a circular ADHD argument, and logically flawed. Fifth, the findings of the 2008 study were not replicated in the 2015 study by Snyder et al. [34]. This was explained by an increase in the prevalence of ADHD and subsequent overdiagnosis. However, the findings of Arns et al. [33], showing an increase in TBR in the control group, were not discussed. Therefore, Loo argued that TBR should not be used to diagnose or assist in the diagnosis of ADHD. Furthermore, Arns et al. [36] published an article in 2016, reporting that the FDA approval of the NEBA system was inappropriate. In the article, the authors pointed out the methodological errors and also pointed out the doctrine of the caveat emptor to support their stance that the NEBA system should not be used in clinical settings.

In response, Stein et al. [37] argued that NEBA was not approved by the FDA for the diagnosis of ADHD, but rather as an integration method to assist in diagnosis. Additionally, they highlighted that children with symptoms of ADHD who have a low TBR are likely to have other conditions (head injury, sensory deficit, etc.). Their answers to the errors suggest- ed by Arns et al. [36] are as follows: First, Arns et al. argued that the results on TBR were heterogeneous and inconsistent, and that the effect size decreased. Stein et al. reported that an increase in the prevalence of ADHD led to a large number of false-positive cases. Second, with regard to Arns' argument on the expertise of FDA reviewers, Stein et al. reported that the reviewers were psychology, psychiatry, neurology, and pediatric experts and that Class III regulatory pathways of FDA require the highest level of evidence. Lastly, to support the reliability of NEBA, the authors reported that NEBA had consistent effects based on research protocols used in 13 independent institutions, even though the prevalence of ADHD varied by region.

\section{Theta/beta ratio: tentative conclusions}

Until 2010, TBR was a biomarker candidate for ADHD that consistently showed a high diagnostic value. However, in recent studies, limitations of TBR have been reported. This is, in part, caused by the heterogeneity in ADHD, which is a hallmark of all mental disorders. The universal applicability of TBR is still debated. According to Snyder et al. [34], some children diagnosed with ADHD are misdiagnosed as having other diseases, and that EEG can distinguish ADHD. Therefore, to overcome these limitations, future studies must assess the heterogeneity of ADHD using various biomarkers, including EEG, MRI, and genes.

\section{Theta phase-gamma amplitude coupling}

Cross-frequency coupling is an index calculated by combining the neural oscillations of two different frequency domains. This reflects the synchronization between the local and global networks of the brain [38]. In particular, the slower oscillation EEG phase often controls the amplitude, frequency, and the faster EEG phase [39]. Phase-amplitude coupling (PAC) is considered a promising biomarker of mental disorders, and it is expected to infer dysfunction from the whole brain network concept instead of simple measurements of the changes in power of a specific frequency [40]. The most actively studied PAC is TGC, which is closely related to general cognitive functions, including working memory [41,42], language [43], and attention [44]. In particular, the increase in resting TGC in patients with schizophrenia is associated with dysfunction of the default mode network $[45,46]$ and has been actively studied.

TGC is also a promising biological marker of ADHD in children. In a study by Kim et al. [47], children with ADHD showed a significantly lower level of TGC compared to the control group of healthy children, in the resting state. In this study, TGC showed a high accuracy of $71.7 \%$ compared to that of TBR (58.7\%). In addition, children with ADHD showed a rapid decrease in synchronization when they performed mental 
arithmetic, in contrast to children without $\mathrm{ADHD}$, who showed no changes in synchronization [48]. This suggested that the normal transition process of suppressing 'task-negative' default mode network and activating 'task-positive' attentional network does not occur in children with ADHD. Rather, only the 'task-negative' default mode network is suppressed in those children. These findings highlighted the potential of TGC as a biological marker to assess problems in attentional set shifting in ADHD.

PAC, including TGC, is an interesting marker for different mental disorders. However, its underlying mechanism has not been fully elucidated. Further research is required to assess the mechanism of PAC as a marker for cognitive function and mental disorders.

\section{SUBGROUPING}

Patients with ADHD have varying symptom profiles, responses to medications, progress, and prognosis. Therefore, attempts have been made to subgroup ADHD according to symptoms. In the DSM-IV, subtyping was attempted according to inattention and hyperactivity-impulsivity symptoms. However, the term "subtype" in DSM-IV was changed to "current presentation" in the DSM-5. This was to reflect the results of studies showing that clinical symptoms of ADHD change according to lifestyle and development [49,50]. In recent years, studies have actively assessed the heterogeneity of ADHD through dimensional approaches, including research domain criteria $(\mathrm{RDoC})$ and hierarchical taxonomy of psychopathology (HiTOP) to overcome the limitations of the DSM diagnosis systems based on clinical symptoms. In particular, machine learning studies have used MRI to subgroup and analyze the characteristics of ADHD [51-53] and these have made rapid progress. Similarly, QEEG has also been suggested as a promising research tool for ADHD subgrouping [54].

In early studies, three subgroups of ADHD were observed using QEEG [55]. The first group was a maturational lag type with increased slow waves and decreased fast waves. During the normal transition from childhood to adolescence, slow waves decreased and fast waves increased in EEG. The maturational lag type suggests that brain development is slower in children with ADHD than in children without ADHD. Differences have been observed in the maturational lag type when comparing children of the same age with and without ADHD, but not when compared with children of younger ages. The second group was the hypoarousal type. In this group, both the theta and beta waves were increased. This translated into an increased TBR. Previous studies that reported on ADHD with increased TBR might have been biased and included many cases of this hypoarsoual ADHD type. This subgroup is asso- ciated with thalamo-cortical dysrhythmia and shows a similar pattern on the QEEG, which is also observed in different mental disorders [56]. In a recent study, 35\% of children with ADHD showed this hypoarousal type with an increased TBR and were clearly distinguished from other subgroups [57]. The third subgroup was the hyperarousal type, observed in $20 \%$ of the children with ADHD. It is characterized by hyperactive beta waves and is more common in boys. This subgroup leads to more comorbidities and increased complaints of temper tantrums [58]. This subgroup also showed a poor response to medication [59]. In a recent study, Clarke et al. [60] included subjects with ADHD who had comorbid mental disorders $(n=155)$ and observed a fourth subtype, with increased alpha waves. This group showed a significantly high response to the confused or fog' state on the Child Behavior Checklist and demonstrated increased ritualistic behaviors and hyperactivity.

Loo et al. [61] analyzed the QEEG of 781 participants (620 ADHD and 161 control) and classified them into five classes. The five classes were named based on the frequency of the most dominant EEG: delta (30\%), theta (23\%), alpha (20\%), beta (7\%), and no spectral elevation (NSE; 20\%). The authors observed that the subgroup with prominent delta and theta waves was associated with disruptive behavior and cognitive dysfunction, while those with prominent alpha and beta waves were associated with emotional dysregulation and internalizing behavior. Additionally, the authors stated that in previous studies, comorbid mood disorders were excluded, which led to subgroups with prominent delta and theta waves and subsequently high TBR. The NSE subgroup, which showed no increase in the power spectrum at any frequency band, showed

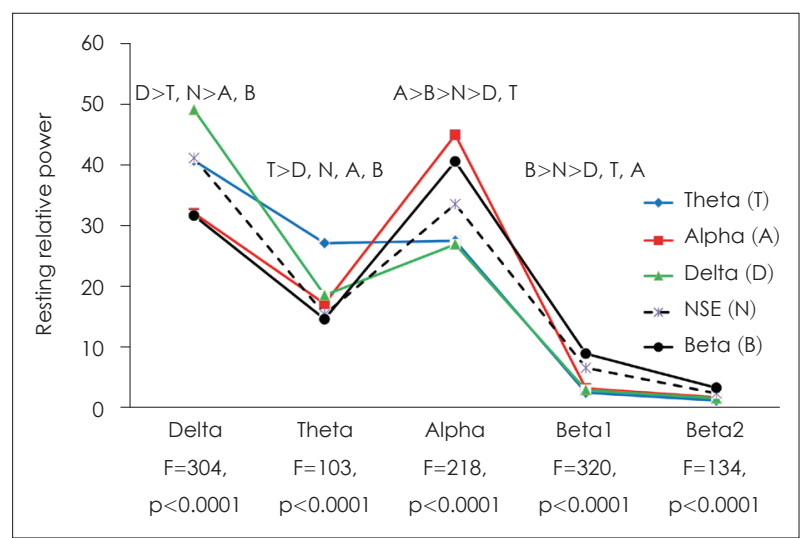

Fig. 1. Spectral Power Profiles for EEG-based subgroups. Relative power in the parietal region (P3, Pz, and P4) across the frequency bands for each of the five empirically defined subgroups. Each group is named for the frequency band where the power is significantly elevated above the other clusters. Degrees of freedom for EEG analyses F[4775]. Post hoc results $(p<0.05)$ for each frequency band were located above the spectral elevation for each frequency band. EEG: electroencephalogram. Adapted from Loo et al. J Child Psychol Psychiatr 2018;59:223231, with permission of John Wiley and Sons [61]. 
relatively fewer behavioral and cognitive function problems. This subgroup was observed in all ADHD and typically developing control groups. This suggests that the clinical diagnosis of ADHD may show no specific abnormalities on EEG.

Byeon et al. [62] also confirmed the heterogeneity of ADHD by subgrouping using QEEG. In this study, 74 children were divided into three groups: ADHD, not other specified (NOS), and neurotypical (NT), and cluster analysis further divided the participants into four subgroups. In addition to the maturational lag and hypoarousal types, a new type with increased alpha waves was observed. This subgroup contained the high- est proportion of NOS (ADHD 30\%, NOS 59\%, NT 11\%), suggesting that childhood depression showed similar symptoms to ADHD and was misdiagnosed.

Based on the findings of studies that subgrouped ADHD using QEEG, ADHD is heterogeneous, and several subtypes can be identified. In particular, the subtype with increased alpha waves. Alpha is presumed to be associated with mood (depression and emotional dysregulation). This is also consistent with the statement of Snyder et al. [34] that low TBR is not pure ADHD, but a condition or comorbidity that has symptoms similar to ADHD. Further research is required regarding

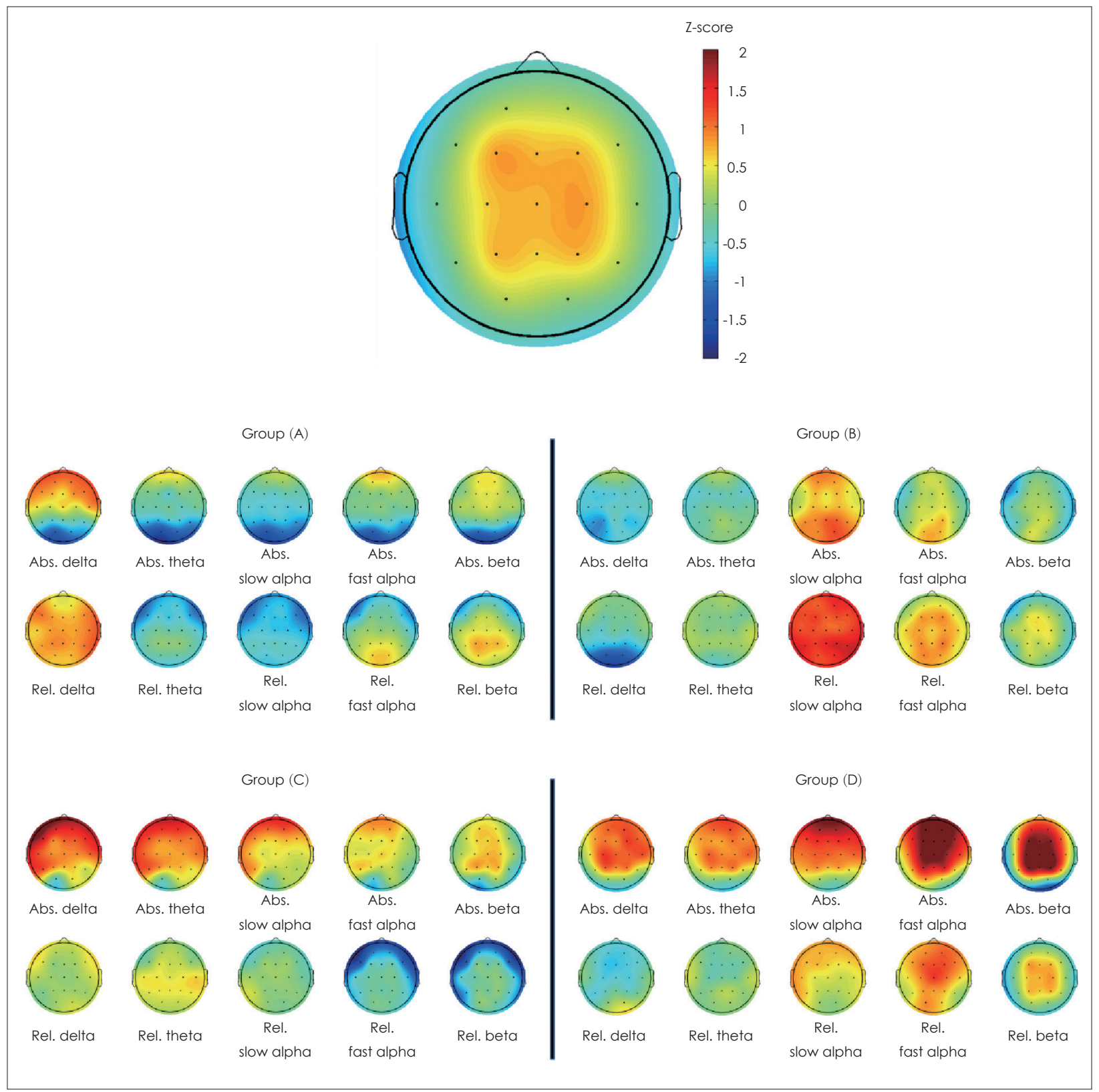

Fig. 2. The difference in topography between the 4 subtypes divided by cluster analysis of quantitative electroencephalogram. Adapted from Byeon et al. PLOS ONE 2020;15:e0242566 [62]. 
Table 1. Characteristics of studies on QEEG subgroups in ADHD

\begin{tabular}{|c|c|c|c|c|c|c|}
\hline \multirow[t]{2}{*}{ Study (years) } & \multicolumn{2}{|c|}{$\mathrm{N}$} & \multicolumn{2}{|c|}{$\begin{array}{c}\text { Clinical } \\
\text { characteristics }\end{array}$} & \multirow{2}{*}{$\begin{array}{l}\text { Number of } \\
\text { subgroups }\end{array}$} & \multirow[t]{2}{*}{ Results } \\
\hline & ADHD & Control & Age & Male (\%) & & \\
\hline $\begin{array}{l}\text { Clarke et al. [55] } \\
(2001)\end{array}$ & 184 & 40 & $8-12$ & 100 & 3 & $\begin{array}{l}\text { Cluster } 1 \text { (hypoarousal type): } 42.3 \% \\
\text { Cluster } 2 \text { (maturational lag type): } 37.5 \% \\
\text { Cluster } 3 \text { (hyperarousal type): } 20.2 \%\end{array}$ \\
\hline $\begin{array}{l}\text { Clarke et al. [60] } \\
(2011)\end{array}$ & 155 & 109 & $7-13$ & 100 & 5 & $\begin{array}{l}\text { Cluster } 1 \text { (hyperarousal type): } 23.2 \% \\
\text { Cluster 2* (hypoarousal type): } 11 \% \\
\text { Cluster } 3 \text { (maturational lag type): } 24.5 \% \\
\text { Cluster } 4 * \text { (hypoarousal type): } 24.5 \% \\
\text { Cluster } 5: 16.8 \% \\
{ }^{*} \text { Cluster } 2 \text { and } 4 \text { has a same QEEG profile. Total } 35.5 \%\end{array}$ \\
\hline $\begin{array}{l}\text { Loo et al. [61] } \\
\text { (2018) }\end{array}$ & 620 & 161 & $6-18$ & 59 & 5 & $\begin{array}{l}\text { Delta group: } 30 \% \\
\text { Theta group: } 23 \% \\
\text { Alpha group: } 20 \% \\
\text { Beta group: } 7 \% \\
\text { No spectral elevation group: } 20 \%\end{array}$ \\
\hline $\begin{array}{l}\text { Byeon et al. [62] } \\
(2020)\end{array}$ & $\begin{array}{l}59(32 ; \\
\text { ADHD } \\
\text { NOS) }\end{array}$ & 15 & $7-12$ & 78 & 4 & $\begin{array}{l}\text { Cluster } 1 \text { (maturational lag type): ADHD (46\%), NOS (33\%), } \\
\text { NT ( } 21 \% \text { ) } \\
\text { Cluster } 2 \text { (childhood depression): ADHD (30\%), NOS (59\%), } \\
\text { NT ( } 11 \% \text { ) } \\
\text { Cluster } 3 \text { (hypoarousal type): ADHD (47\%), NOS (40\%), } \\
\text { NT (13\%) } \\
\text { Cluster } 4 \text { (relatively normal): ADHD (13\%), NOS }(25 \%), \\
\text { NT (62\%) }\end{array}$ \\
\hline
\end{tabular}

ADHD: attention deficit/hyperactivity disorder, NOS: not other specified, NT: neurotypical, QEEG: quantitative electroencephalogram

the subgroups of ADHD, and these studies are important for clinical diagnosis and treatment of ADHD.

\section{CONCLUSION}

TBR is the most studied QEEG diagnostic index for ADHD; however, recent studies have argued that TBR is not a valid biological marker, as the control group showed increased TBR and heterogeneity of ADHD. Therefore, new indices, such as TGC, would be useful for diagnosing ADHD, and further studies on such new indices are necessary. A dimensional approach, including RDoC and HiTOP, may help assess the heterogeneity of ADHD, and more specific studies through subgrouping will increase our understanding of ADHD. Systematic and large-scale studies or meta-analyses are necessary to demonstrate a high level of evidence for the use of QEEG in ADHD diagnosis.

\section{Acknowledgments}

This work was supported by a National Research Foundation of Korea (NRF) grant funded by the Korean Ministry of Science, ICT \& Future Planning (NRF-2018R1C1B5041143).

\section{Conflicts of Interest}

The authors have no potential conflicts of interest to disclose.

\section{Author Contributions}

Conceptualization: Su Hyun Bong, Jun Won Kim. Data curation: Su Hyun Bong, Jun Won Kim. Funding acquisition: Jun Won Kim. Investigation: Su Hyun Bong, Jun Won Kim. Project administration: Su Hyun Bong, Jun Won Kim. Supervision: Jun Won Kim. Validation: Su Hyun Bong, Jun Won Kim. Visualization: Su Hyun Bong, Jun Won Kim. Writing_original draft: Su Hyun Bong. Writing_review \& editing: Jun Won Kim.

\section{ORCID iDs}

Su Hyun Bong https://orcid.org/0000-0002-9492-9501

Jun Won Kim https://orcid.org/0000-0001-6793-3006

\section{REFERENCES}

1) American Psychiatric Association. Diagnostic and statistical manual of mental disorders: DSM-5. 5th ed. Arlington, VA: American Psychiatric Association;2013.

2) Sayal K, Prasad V, Daley D, Ford T, Coghill D. ADHD in children and young people: prevalence, care pathways, and service provision. Lancet Psychiatry 2018;5:175-186.

3) Biederman J, Faraone S, Milberger S, Curtis S, Chen L, Marrs A, et al. Predictors of persistence and remission of ADHD into adolescence: results from a four-year prospective follow-up study. J Am Acad Child Adolesc Psychiatry 1996;35:343-351. 
4) Barkley RA, Fischer M, Edelbrock CS, Smallish L. The adolescent outcome of hyperactive children diagnosed by research criteria: I. An 8-year prospective follow-up study. J Am Acad Child Adolesc Psychiatry 1990;29:546-557.

5) Barkley RA, Fischer M, Smallish L, Fletcher K. The persistence of attention-deficit/hyperactivity disorder into young adulthood as a function of reporting source and definition of disorder. J Abnorm Psychol 2002;111:279-289.

6) Lara C, Fayyad J, de Graaf R, Kessler RC, Aguilar-Gaxiola S, Angermeyer M, et al. Childhood predictors of adult attention-deficit/ hyperactivity disorder: results from the World Health Organization World Mental Health Survey Initiative. Biol Psychiatry 2009; 65:46-54.

7) Sonuga-Barke EJ, Halperin JM. Developmental phenotypes and causal pathways in attention deficit/hyperactivity disorder: potential targets for early intervention? J Child Psychol Psychiatry 2010; 51:368-389.

8) Ross DM, Ross SA. Hyperactivity: research, theory, and action. New York, NY: Wiley;1976.

9) Gizer IR, Ficks C, Waldman ID. Candidate gene studies of ADHD: a meta-analytic review. Hum Genet 2009;126:51-90.

10) Hart H, Radua J, Mataix-Cols D, Rubia K. Meta-analysis of fMRI studies of timing in attention-deficit hyperactivity disorder (ADHD). Neurosci Biobehav Rev 2012;36:2248-2256.

11) Lee MS, Park SB, Kim GM, Kim HJ, Park S, Kim Y, et al. The revised Korean practice parameter for the treatment of attentiondeficit hyperactivity disorder (II)-diagnosis and assessment. J Korean Acad Child Adolesc Psychiatry 2017;28:58-69.

12) Hunter AM, Muthén BO, Cook IA, Leuchter AF. Antidepressant response trajectories and quantitative electroencephalography (QEEG) biomarkers in major depressive disorder. J Psychiatr Res 2010;44: 90-98.

13) Jokić-Begić N, Begić D. Quantitative electroencephalogram (qEEG) in combat veterans with post-traumatic stress disorder (PTSD). Nord J Psychiatry 2003;57:351-355.

14) Kim JW, Lee YS, Han DH, Min KJ, Lee J, Lee K. Diagnostic utility of quantitative EEG in un-medicated schizophrenia. Neurosci Lett 2015;589:126-131.

15) Alper KR, Prichep LS, Kowalik S, Rosenthal MS, John ER. Persistent QEEG abnormality in crack cocaine users at 6 months of drug abstinence. Neuropsychopharmacology 1998;19:1-9.

16) Tot S, Ozge A, Cömelekoğlu U, Yazici K, Bal N. Association of QEEG findings with clinical characteristics of OCD: evidence of left frontotemporal dysfunction. Can J Psychiatry 2002;47:538545.

17) Monastra VJ, Lubar JF, Linden M, VanDeusen P, Green G, Wing W, et al. Assessing attention deficit hyperactivity disorder via quantitative electroencephalography: an initial validation study. Neuropsychology 1999;13:424-433.

18) Barry RJ, Clarke AR. Spontaneous EEG oscillations in children, adolescents, and adults: typical development, and pathological aspects in relation to AD/HD. J Psychophysiol 2009;23:157-173.

19) Mann CA, Lubar JF, Zimmerman AW, Miller CA, Muenchen RA. Quantitative analysis of EEG in boys with attention-deficit-hyperactivity disorder: controlled study with clinical implications. Pediatr Neurol 1992;8:30-36.

20) Lubar JF. Discourse on the development of EEG diagnostics and biofeedback for attention-deficit/hyperactivity disorders. Biofeedback Self Regul 1991;16:201-225.

21) Snyder SM, Hall JR. A meta-analysis of quantitative EEG power associated with attention-deficit hyperactivity disorder. J Clin Neurophysiol 2006;23:440-455

22) Snyder SM, Quintana H, Sexson SB, Knott P, Haque AF, Reynolds DA. Blinded, multi-center validation of EEG and rating scales in identifying ADHD within a clinical sample. Psychiatry Res 2008;
159:346-358.

23) FDA. De novo classification request for neuropsychiatric EEGbased assessment aid for ADHD (NEBA) system [updated 2013; cited 2021 Apr 15]. Available from URL: www.accessdata.fda. gov/cdrh_docs/reviews/K112711.pdf.

24) FDA. FDA permits marketing of first brain wave test to help assess children and teens for ADHD [updated 2013 Jul 15; cited 2021 Apr 15]. Available from URL: www.fda.gov/NewsEvents/Newsroom/PressAnnouncements/ucm360811.htm.

25) Barry RJ, Clarke AR, Johnstone SJ, Brown CR. EEG differences in children between eyes-closed and eyes-open resting conditions. Clin Neurophysiol 2009;120:1806-1811.

26) Barry RJ, Clarke AR, Johnstone SJ, McCarthy R, Selikowitz M. Electroencephalogram theta/beta ratio and arousal in attentiondeficit/hyperactivity disorder: evidence of independent processes. Biol Psychiatry 2009;66:398-401.

27) Clarke AR, Barry RJ, Dupuy FE, McCarthy R, Selikowitz M, Johnstone SJ. Excess beta activity in the EEG of children with attention-deficit/hyperactivity disorder: a disorder of arousal? Int J Psychophysiol 2013;89:314-319.

28) Clarke AR, Barry RJ, Karamacoska D, Johnstone SJ. The EEG theta/beta ratio: a marker of arousal or cognitive processing capacity? Appl Psychophysiol Biofeedback 2019;44:123-129.

29) Coolidge FL, Starkey MT, Cahill BS. Comparison of a parent-rated DSM-IV measure of attention-deficit/hyperactivity disorder and quantitative EEG parameters in an outpatient sample of children. J Clin Neurophysiol 2007;24:348-351.

30) Ogrim G, Kropotov J, Hestad K. The quantitative EEG theta/beta ratio in attention deficit/hyperactivity disorder and normal controls: sensitivity, specificity, and behavioral correlates. Psychiatry Res 2012;198:482-488.

31) Buyck I, Wiersema JR. Resting electroencephalogram in attention deficit hyperactivity disorder: developmental course and diagnostic value. Psychiatry Res 2014;216:391-397.

32) Loo SK, Cho A, Hale TS, McGough J, McCracken J, Smalley SL. Characterization of the theta to beta ratio in ADHD: identifying potential sources of heterogeneity. J Atten Disord 2013;17:384392.

33) Arns M, Conners CK, Kraemer HC. A decade of EEG theta/beta ratio research in ADHD: a meta-analysis. J Atten Disord 2013;17:374383.

34) Snyder SM, Rugino TA, Hornig M, Stein MA. Integration of an EEG biomarker with a clinician's ADHD evaluation. Brain Behav 2015;5:e00330.

35) Loo SK, Arns M. Should the EEG-based theta to beta ratio be used to diagnose ADHD? The ADHD Report 2015;23:8-13.

36) Arns M, Loo SK, Sterman MB, Heinrich H, Kuntsi J, Asherson P, et al. Editorial perspective: how should child psychologists and psychiatrists interpret FDA device approval? Caveat emptor. J Child Psychol Psychiatry 2016;57:656-658.

37) Stein MA, Snyder SM, Rugino TA, Hornig M. Commentary: objective aids for the assessment of ADHD-further clarification of what FDA approval for marketing means and why NEBA might help clinicians. A response to Arns et al. (2016). J Child Psychol Psychiatry 2016;57:770-771.

38) Canolty RT, Knight RT. The functional role of cross-frequency coupling. Trends Cogn Sci 2010;14:506-515.

39) Jerath R, Beveridge C, Jensen M. On the hierarchical organization of oscillatory assemblies: layered superimposition and a global bioelectric framework. Front Hum Neurosci 2019;13:426.

40) Sacks DD, Schwenn PE, McLoughlin LT, Lagopoulos J, Hermens DF. Phase-amplitude coupling, mental health and cognition: implications for adolescence. Front Hum Neurosci 2021;15:622313.

41) Kaminski M, Brzezicka A, Kaminski J, Blinowska KJ. Coupling between brain structures during visual and auditory working memory 
tasks. Int J Neural Syst 2019;29:1850046.

42) Axmacher N, Henseler MM, Jensen O, Weinreich I, Elger CE, Fell J. Cross-frequency coupling supports multi-item working memory in the human hippocampus. Proc Natl Acad Sci U S A 2010;107: 3228-3233.

43) Doesburg SM, Vinette SA, Cheung MJ, Pang EW. Theta-modulated gamma-band synchronization among activated regions during a verb generation task. Front Psychol 2012;3:195.

44) Gonzalez-Trejo E, Mögele H, Pfleger N, Hannemann R, Strauss DJ. Electroencephalographic phase-amplitude coupling in simulated driving with varying modality-specific attentional demand. IEEE Trans Hum Mach Syst 2019;49:589-598.

45) Lee TH, Kim M, Hwang WJ, Kim T, Kwak YB, Kwon JS. Relationship between resting-state theta phase-gamma amplitude coupling and neurocognitive functioning in patients with first-episode psychosis. Schizophr Res 2020;216:154-160.

46) Won GH, Kim JW, Choi TY, Lee YS, Min KJ, Seol KH. Thetaphase gamma-amplitude coupling as a neurophysiological marker in neuroleptic-naïve schizophrenia. Psychiatry Res 2018;260:406411.

47) Kim JW, Lee J, Kim BN, Kang T, Min KJ, Han DH, et al. Thetaphase gamma-amplitude coupling as a neurophysiological marker of attention deficit/hyperactivity disorder in children. Neurosci Lett 2015;603:25-30.

48) Kim JW, Kim BN, Lee J, Na C, Kee BS, Min KJ, et al. Desynchronization of theta-phase gamma-amplitude coupling during a mental arithmetic task in children with attention deficit/hyperactivity disorder. PLoS One 2016;11:e145288.

49) Hurtig T, Ebeling H, Taanila A, Miettunen J, Smalley SL, McGough JJ, et al. ADHD symptoms and subtypes: relationship between childhood and adolescent symptoms. J Am Acad Child Adolesc Psychiatry 2007;46:1605-1613.

50) Epstein JN, Loren RE. Changes in the definition of ADHD in DSM5: subtle but important. Neuropsychiatry (London) 2013;3:455-458

51) Lecei A, van Hulst BM, de Zeeuw P, van der Pluijm M, Rijks $Y$, Durston S. Can we use neuroimaging data to differentiate between subgroups of children with ADHD symptoms: a proof of concept study using latent class analysis of brain activity. Neuroimage Clin 2019;21:101601.

52) Qureshi MN, Min B, Jo HJ, Lee B. Multiclass classification for the differential diagnosis on the ADHD subtypes using recursive feature elimination and hierarchical extreme learning machine: structural MRI study. PLoS One 2016;11:e0160697.

53) Qian X, Castellanos FX, Uddin LQ, Loo BRY, Liu S, Koh HL, et al. Large-scale brain functional network topology disruptions underlie symptom heterogeneity in children with attention-deficit/ hyperactivity disorder. Neuroimage Clin 2019;21:101600.

54) Karalunas SL, Nigg JT. Heterogeneity and subtyping in attentiondeficit/hyperactivity disorder-considerations for emerging research using person-centered computational approaches. Biol Psychiatry 2020;88:103-110.

55) Clarke AR, Barry RJ, McCarthy R, Selikowitz M. EEG-defined subtypes of children with attention-deficit/hyperactivity disorder. Clin Neurophysiol 2001;112:2098-2105.

56) Llinás RR, Ribary U, Jeanmonod D, Kronberg E, Mitra PP. Thalamocortical dysrhythmia: a neurological and neuropsychiatric syndrome characterized by magnetoencephalography. Proc Natl Acad Sci U S A 1999;96:15222-15227.

57) Bussalb A, Collin S, Barthélemy Q, Ojeda D, Bioulac S, BlascoFontecilla $\mathrm{H}$, et al. Is there a cluster of high theta-beta ratio patients in attention deficit hyperactivity disorder? Clin Neurophysiol 2019;130:1387-1396.

58) Clarke AR, Barry RJ, McCarthy R, Selikowitz M. Excess beta activity in children with attention-deficit/hyperactivity disorder: an atypical electrophysiological group. Psychiatry Res 2001;103:205218.

59) Clarke AR, Barry RJ, McCarthy R, Selikowitz M. EEG differences between good and poor responders to methylphenidate and dexamphetamine in children with attention-deficit/hyperactivity disorder. Clin Neurophysiol 2002;113:194-205.

60) Clarke AR, Barry RJ, Dupuy FE, Heckel LD, McCarthy R, Selikowitz M, et al. Behavioural differences between EEG-defined subgroups of children with attention-deficit/hyperactivity disorder. Clin Neurophysiol 2011;122:1333-1341.

61) Loo SK, McGough JJ, McCracken JT, Smalley SL. Parsing heterogeneity in attention-deficit hyperactivity disorder using EEGbased subgroups. J Child Psychol Psychiatry 2018;59:223-231.

62) Byeon J, Choi TY, Won GH, Lee J, Kim JW. A novel quantitative electroencephalography subtype with high alpha power in ADHD: ADHD or misdiagnosed ADHD? PLoS One 2020;15:e0242566. 